\title{
Medical Image of the Week: Hematopneumatoceles from Pulmonary Lacerations
}

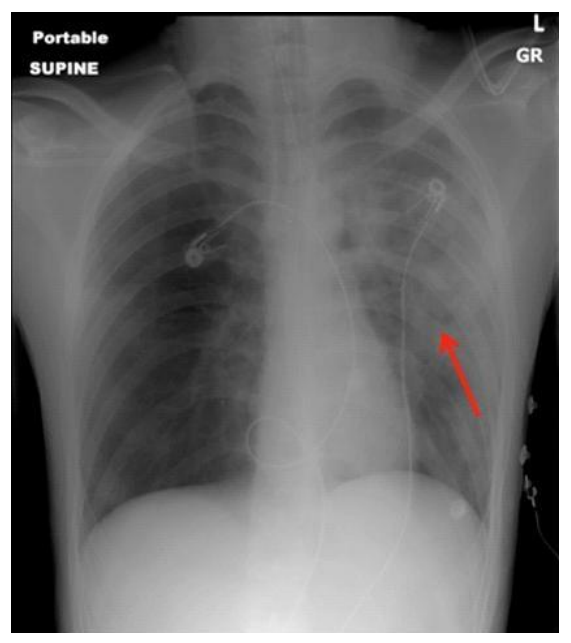

Figure 1. Chest $x$-ray showing irregular patchy regions of ill-defined consolidation in the left upper lobe and lingula, as well as suggestion of cystic changes (arrow).

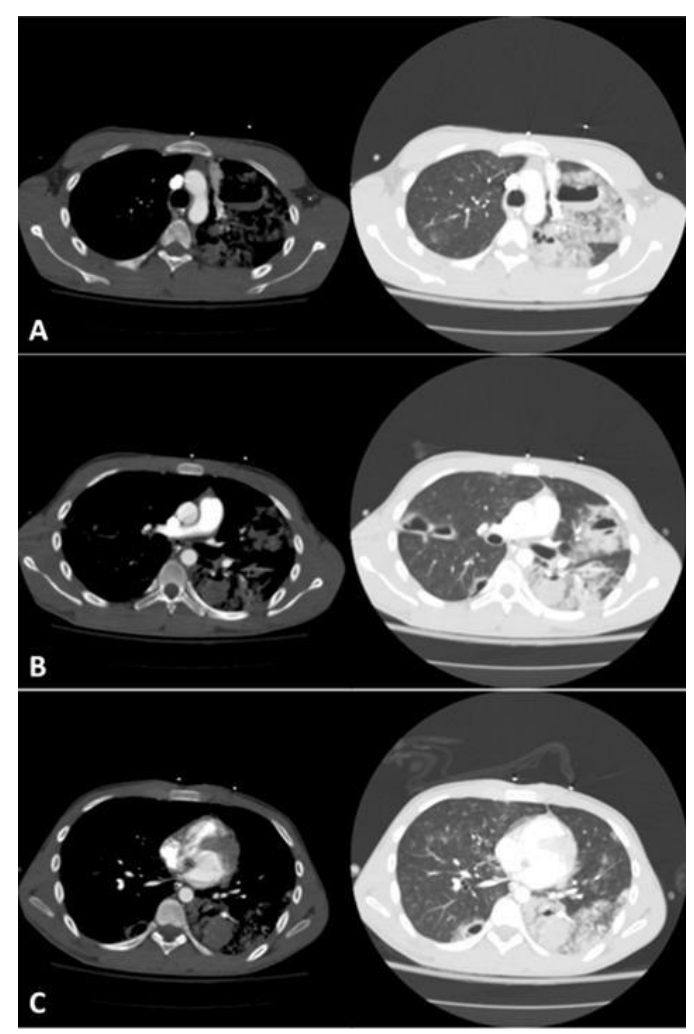

Figure 2. Chest CT axial views, soft tissue and lung windows at the level of the aortic arch (A), right pulmonary artery $(B)$ and the heart $(C)$ showing mixed consolidative and nodular left lung opacities suggestive of pulmonary contusions, as well as contrecoup injury in the right lung, in addition to multiple cystic spaces containing air-fluid levels consistent with pulmonary lacerations. 


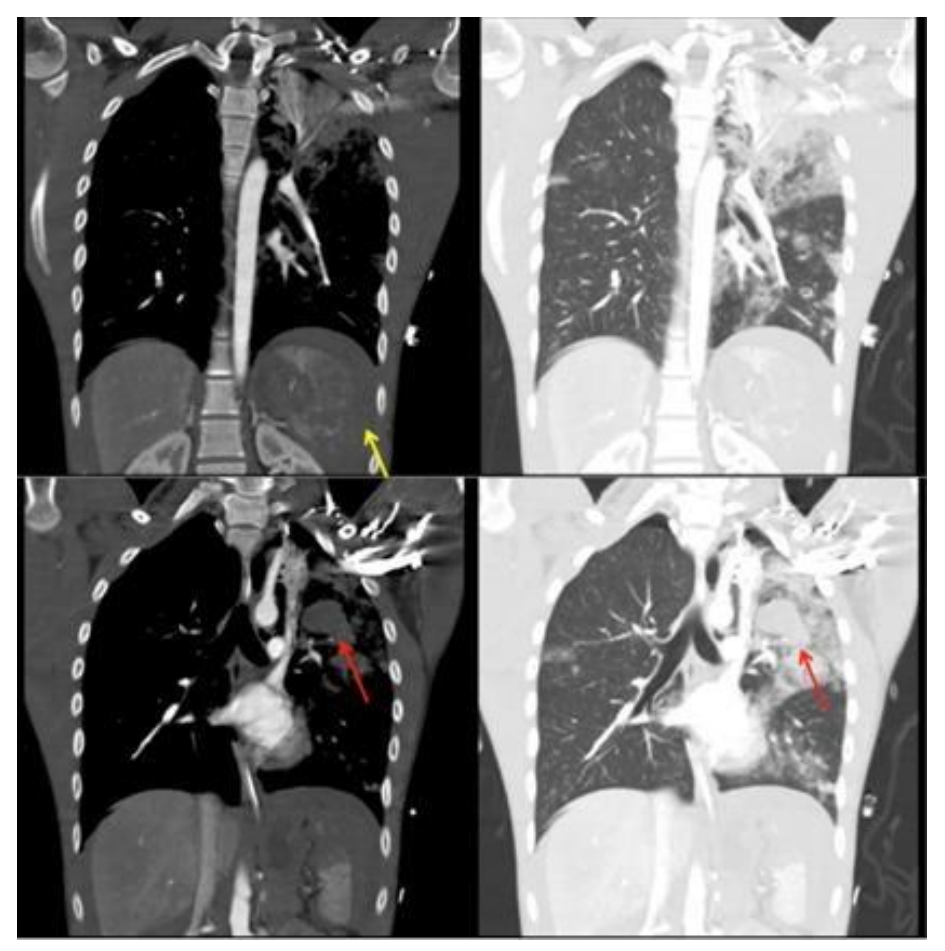

Figure 3. Chest CT coronal views, soft tissue and lung windows showing consolidative and nodular lung opacities as well as fluid layering in cystic spaces (red arrows). A shattered spleen (yellow arrow) is also seen.

A 17-year-old man was brought to the emergency room after a fall from a 50 foot bridge. He was hypoxemic on presentation, requiring endotracheal intubation. Chest computed tomography (CT) revealed bilateral airspace opacities consistent with pulmonary contusions, and multiple air-fluid levels diagnostic of pulmonary lacerations (Figures 1-3).

Pulmonary lacerations are rare complications of blunt chest trauma (1). They can be contained within the lung parenchyma or may extend through the visceral pleura causing a pneumothorax. Due to its elastic recoil, the surrounding lung tissue pulls back from the laceration resulting in a round or oval cavity that may fill with air (pneumatocele), blood (hematocele) or both (hematopneumatocele). Lacerations are often obscured on chest x-ray as they are usually surrounded by contusion, requiring a CT for detection (2). They are classified into four types according to the mechanism of injury: Type 1 (compression rupture injury, most common type, usually centrally located), Type 2 (shearing against the thoracic spine, involving the paraspinal region of the lower lobes), Type 3 (rib penetration into the lung periphery, usually associated with a pneumothorax) and Type 4 (adhesion tear, in regions of pleuropulmonary adhesions) (3). Pulmonary lacerations heal more slowly than contusions and may last up to several months, over time becoming increasingly filled with blood, before regressing (2).

Our patient underwent an exploratory laparotomy with a splenectomy. The pulmonary lacerations were managed conservatively. He was successfully extubated on day\#10 and discharged home on day\#14 with a plan to follow his lacerations with monthly chest radiography. 
Udit Chaddha MD1, Darren Maehara MD¹, loan Puscas DOㄹ, Ashley Prosper $\mathrm{MD}^{2}$, and Ramyar Mahdavi MD ${ }^{1}$

${ }^{1}$ Division of Pulmonary, Critical Care and Sleep Medicine and ${ }^{2}$ Department of Radiology

Keck School of Medicine of the University of Southern California Los Angeles, CA USA

\section{References}

1. Nishiumi N, Maitani F, Tsurumi T, Kaga K, Iwasaki M, Inoue H. Blunt chest trauma with deep pulmonary laceration. Ann Thorac Surg. 2001;71(1):3148. [CrossRef] [PubMed]

2. Kaewlai R, Avery LL, Asrani AV, Novelline RA. Multidetector CT of blunt thoracic trauma. Radiographics. 2008;28(6):1555-70. [CrossRef] [PubMed]

3. Wagner RB, Crawford WO, Schimpf PP. Classification of parenchymal injuries of the lung. Radiology. 1988;167(1):77-82. [CrossRef] [PubMed] 